\title{
Harmine and Harmaline Downregulate TCDD-Induced Cyp1a1 in the Livers and Lungs of C57BL/6 Mice
}

\author{
Mohamed A. M. El Gendy and Ayman O. S. El-Kadi \\ Faculty of Pharmacy and Pharmaceutical Sciences, University of Alberta, Edmonton, AB, Canada T6G 2E1 \\ Correspondence should be addressed to Ayman O. S. El-Kadi; aelkadi@pharmacy.ualberta.ca
}

Received 28 July 2012; Revised 24 September 2012; Accepted 24 September 2012

Academic Editor: Leandro Machado Rocha

Copyright (c) 2013 M. A. M. El Gendy and A. O. S. El-Kadi. This is an open access article distributed under the Creative Commons Attribution License, which permits unrestricted use, distribution, and reproduction in any medium, provided the original work is properly cited.

\begin{abstract}
We previously demonstrated that Peganum harmala L. extract and its main active constituents, harmine and harmaline inhibit the 2,3,7,8-tetrachlorodibenzo- $p$-dioxin (TCDD)-mediated induction of the carcinogen-activating enzyme, Cypla1, in vitro. However, the effect of both alkaloids on Cypla1 in vivo has not been investigated. Therefore, the aim of this study is to examine the effect of harmine and harmaline on TCDD-mediated induction of Cypla1 in mice livers and lungs. C57BL/6 male mice were distributed into four groups $(n=6)$. First group received vehicle, while the second group received TCDD (i.p.). The third and fourth groups received either harmine or harmaline (i.p.) $\times 3$ times along with TCDD one time with the mid dose of harmine and harmaline. All mice were sacrificed after $14 \mathrm{~h}$ from TCDD injection, and livers and lungs were isolated. The effect of harmine and harmaline on TCDD-mediated induction of Cypla1 mRNA, protein, and activity levels was determined using real-time PCR, Western blot analysis, and 7-ethoxyresurofin as a substrate, respectively. Our results showed that harmine and harmaline significantly decreased the TCDD-mediated induction of Cyplal in both the livers and lungs. We concluded that harmine and harmaline are promising candidate to inhibit TCDD-mediated induction of Cypla1 in mice hepatic and extrahepatic tissues.
\end{abstract}

\section{Introduction}

2,3,7,8-Tetrachlorodibenzo- $p$-dioxin (TCDD) is a widely distributed environmental contaminant that possesses multiple species- and tissue-specific adverse effects such as tumor promotion, teratogenicity, and immune-, hepato-, cardioand skin toxicity. TCDD is a known carcinogen to animals and humans, and it was classified as a human carcinogen (Group 1) by International Agency of Research on Cancer (IARC) since 1997. In 2009, IARC confirmed that TCDD is a human carcinogen that is correlated to the increased mortality from all types of human cancers combined [1].

The adverse effects of TCDD are mainly mediated through binding and activation of ubiquitous transcription factor called aryl hydrocarbon receptor (AhR). AhR is found inactive in the cytoplasm until it binds to its ligand such as TCDD. Upon ligand binding, AhR gets activated and translocated to the nucleus where it heterodimerizes with another protein called AhR nuclear translocator (ARNT). The formed complex binds to its cognate DNA sequence that is found upstream of several AhR-regulated genes including CYP1A1 [2].

CYP1A1 is a carcinogen-activating enzyme that catalyzes the metabolic activation of several procarcinogens to their ultimate carcinogenic forms. The activity of CYP1A1 has been correlated not only to the exposure to several environmental contaminants such as polycyclic aromatic hydrocarbons (PAHs) but also to the activation of several pro-carcinogenic agents [3]. Moreover, several studies have demonstrated the positive relationship between the induction of CYP1A1 and the incidence of several human cancers such as lung, colon, and rectal cancers $[4,5]$. Additionally, it has been demonstrated that the inhibition of AhR activity and its regulated gene, CYP1A1, could result in the prevention of toxic effects caused by the AhR ligands, including carcinogenicity [6].

Harmine, 7-methoxy-1-methyl-9H-pyrido (3,4-b)indole and harmaline, 4,9-dihydro-7-methoxy-1-methyl-3H-pyrido (3,4-b)indole (Figure 1) are common $\beta$-carboline alkaloids that are present in several plants such as Peganum 


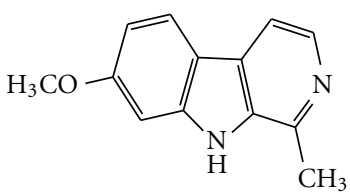

Harmine

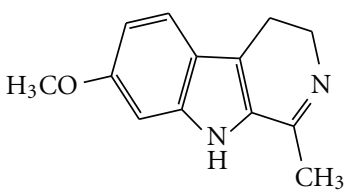

Harmaline

Figure 1: Chemical structure of harmine (7-methoxy-1-methyl-9H-pyrido [3,4-b]indole) and harmaline (4,9-dihydro-7-methoxy-1-methyl3H-pyrido [3,4-b]indole).

harmala L. (Nitrariaceae). Harmine and harmaline possess several pharmacological effects such as hypothermic, antimicrobial, antioxidant, hallucinogenic, cytotoxic, and antitumor properties [7]. We previously demonstrated that Peganum harmala extract and its main active constituents, harmine and harmaline decreased the TCDD-mediated induction of Cypla1 activity in mouse hepatoma Hepa-1c1c7 cells [8]. Moreover, we reported that both harmine and harmaline inhibited the TCDD-mediated induction of the carcinogenactivating enzyme, CYP1A1 in human hepatoma HepG 2 cells through transcriptional and posttranslational mechanisms $[9,10]$. However, the effect of both alkaloids on Cyp1a1 in vivo remains to be examined. Therefore, the aim of this study is to examine the effect of harmine and harmaline on TCDDmediated induction of Cypla1 in mice livers and lungs.

\section{Material and Methods}

2.1. Chemicals and Reagents. Harmine hydrochloride ( $>98 \%$ pure) and 7-ethoxyresorufin (7ER) were purchased from Sigma-Aldrich (St. Louis, MO). TRIzol was obtained from Invitrogen (Carlsbad, CA). Primary antimouse Cypla antibody, primary rabbit antimouse actin and goat anti-rabbit IgG peroxidase secondary antibodies were purchased from Santa Cruz (Santa Cruz, CA). TCDD, >99\% pure, was obtained from Cambridge Isotope Laboratories (Woburn, MA). Harmaline hydrochloride dihydrate ( $>90 \%$ pure) was supplied by ACROS Organics (Morris Plains, NJ). Goat antimouse IgG peroxidase secondary antibody was purchased from R\&D Systems (Minneapolis, MN). High-Capacity cDNA Reverse Transcription Kit and SYBR Green PCR Master Mix were obtained from Applied Biosystems (Foster City, CA). Nitrocellulose membranes were purchased from BioRad (Hercules, CA). Chemiluminescence Western blotting detection reagents were obtained from GE Healthcare Life Sciences (Piscataway, NJ). Primers were purchased from Integrated DNA technologies (IDT, Coralville, IA). All other chemicals were purchased from Fisher Scientific (Toronto, $\mathrm{ON})$.

2.2. Animals. All experimental procedures involving animals were approved by the University of Alberta Health Sciences Animal Policy and Welfare Committee. Twenty-four male C57BL/6 mice weighing 20-25 g were obtained from Charles River Canada (St. Constant, QC, Canada). All animals were exposed to $12 \mathrm{~h}$ light/dark cycles and were allowed free access to food and water.
2.3. Mice Treatment and Tissues Isolation. Twenty-four male C57BL/6 mice were divided randomly into four groups $(n=$ $6)$. The first group served as weight-matched controls and received the same volume of vehicle for the indicated time points. The second group were treated intraperitoneally (i.p.) with TCDD $(15 \mu \mathrm{g} / \mathrm{kg})$ dissolved in corn oil at $0 \mathrm{~h}$. The third and fourth groups were treated either with harmine hydrochloride or harmaline hydrochloride $(10 \mathrm{mg} / \mathrm{kg}$, i.p.) dissolved in normal saline with sonication and heating for 30 minutes at $40^{\circ} \mathrm{C}$ and TCDD $(15 \mu \mathrm{g} / \mathrm{kg}$, i.p.). Harmine hydrochloride and harmaline hydrochloride were administered to mice at $-4,0$, and $+4 \mathrm{~h}$, while TCDD was treated once at $0 \mathrm{~h}$ (Table 1$)$. All animals were sacrificed by cervical dislocation after $+14 \mathrm{~h}$ from TCDD treatment. Liver and lung tissues were excised and divided in two separate parts; one smaller part was kept for total RNA isolation and the larger part was used for microsomal fraction isolation, immediately frozen in liquid nitrogen and stored at $-80^{\circ} \mathrm{C}$ until analysis.

2.4. RNA Isolation and cDNA Synthesis. The total RNA was isolated from frozen tissues using TRIzol reagent, according to the manufacturer's instructions (Invitrogen) and quantified by measuring the absorbance at $260 \mathrm{~nm}$. RNA quality was determined by measuring the 260/280 ratio, and the first strand cDNA was synthesized using the HighCapacity cDNA Reverse Transcription Kit (Applied Biosystems) according to the manufacturer's instructions. Briefly, $1.5 \mu \mathrm{g}$ of total RNA from each sample was added to a mix of $2.0 \mu \mathrm{L}$ of $10 \mathrm{X}$ reverse transcriptase buffer, $0.8 \mu \mathrm{L}$ of $25 \mathrm{X}$ dNTP mix $(100 \mathrm{mM}), 2.0 \mu \mathrm{L}$ of $10 \mathrm{X}$ reverse transcriptase random primers, $1.0 \mu \mathrm{L}$ of MultiScribe reverse transcriptase, and $4.2 \mu \mathrm{L}$ of nuclease-free water. The final reaction mix was kept at $25^{\circ} \mathrm{C}$ for $10 \mathrm{~min}$, heated to $37^{\circ} \mathrm{C}$ for $120 \mathrm{~min}$, heated for $85^{\circ} \mathrm{C}$ for $5 \mathrm{~s}$, and finally cooled to $4^{\circ} \mathrm{C}$ [11].

2.5. Quantification of mRNA Expression by Real-Time Polymerase Chain Reaction (Real-Time PCR). Real-time PCR reactions were performed using an ABI 7500 system (Applied Biosystems, Inc., Foster City, CA) as described previously [12]. The primers used in the current study were chosen from previously published studies $[8,13]$ and were purchased from Integrated DNA Technologies (IDT, Coralville, IA). Mouse Cyp1a1: forward primer 5 -GGT TAA CCA TGA CCG GGA ACT-3', reverse primer 5 -TGC CCA AAC CAA AGA GAG TGA-3', and mouse 18S: forward primer $5^{\prime}-\mathrm{GTA}$ ACC CGT TGA ACC CCA TT- $3^{\prime}$, reverse primer $5^{\prime}$-CCA TCC AAT 
TABLE 1: Representation of different groups of C57BL/6 mice and the dose schedule for each group.

\begin{tabular}{|c|c|c|c|c|}
\hline \multirow{2}{*}{ Treatments groups } & \multicolumn{4}{|c|}{ Time (h) } \\
\hline & -4 & 0 & +4 & +14 \\
\hline Group 1 & Saline & Saline + corn oil & Saline & sacrifice \\
\hline Group 2 & Saline & Saline + TCDD $(15 \mu \mathrm{g} / \mathrm{kg})$ & Saline & sacrifice \\
\hline Group 3 & Harmine $(10$ mg/kg) & Harmine $(10 \mathrm{mg} / \mathrm{kg})+$ TCDD $(15 \mu \mathrm{g} / \mathrm{kg})$ & Harmine (10 mg/kg) & sacrifice \\
\hline Group 4 & Harmaline $(10 \mathrm{mg} / \mathrm{kg})$ & Harmaline $(10 \mathrm{mg} / \mathrm{kg})+\mathrm{TCDD}(15 \mu \mathrm{g} / \mathrm{kg})$ & Harmaline $(10 \mathrm{mg} / \mathrm{kg})$ & sacrifice \\
\hline
\end{tabular}

CGG TAG TAG CG-3'. Assay controls were incorporated onto the same plate, namely, no-template controls to test for the contamination of any assay reagents. The real-time PCR data were analyzed using the relative gene expression $(\Delta \Delta \mathrm{Ct})$ method, as described in Applied Biosystems User Bulletin No. 2 [14].

2.6. Microsomal Fraction Isolation and Western Blot Analysis. Liver and lung microsomal fractions were isolated as described previously [15]. Briefly, frozen tissues were cut into small pieces and homogenized separately in cold sucrose solution ( $1 \mathrm{~g}$ of tissue in $5 \mathrm{~mL}$ of $0.25 \mathrm{M}$ sucrose). Thereafter, the microsomal fractions were separated using differential ultracentrifugation process. The resulted microsomal pellets were reconstituted in ice-cold sucrose solution and stored at $-80^{\circ} \mathrm{C}$ till used. Protein content of each microsomal fraction was determined by Lowry method using bovine serum albumin as a standard [16]. Western blot analysis was performed as described previously [8]. Briefly, microsomal proteins $(2 \mu \mathrm{g})$ were loaded onto a $10 \%$ SDS-PAGE and electrophoretically transferred to a nitrocellulose membrane. The protein blots were blocked for $24 \mathrm{~h}$ at $4^{\circ} \mathrm{C}$ in blocking buffer ( $5 \%$ skim milk powder, $2 \%$ bovine serum albumin, and $0.05 \%(\mathrm{v} / \mathrm{v})$ Tween 20 in Tris-buffered saline solution $(0.15 \mathrm{M}$ sodium chloride, $3 \mathrm{mM}$ potassium chloride, and $25 \mathrm{mM}$ Tris base)). Thereafter, the protein blots were incubated with primary antimouse Cyp1a antibody for $2 \mathrm{~h}$ at room temperature or primary rabbit antimouse actin for $24 \mathrm{~h}$ at $4^{\circ} \mathrm{C}$. Finally, the membranes were incubated with peroxidase-conjugated secondary antibodies for another $1 \mathrm{~h}$, namely, goat antimouse IgG for Cypla, or goat anti-rabbit IgG for actin detection. The formed bands were visualized with the enhanced chemiluminescence method according to the manufacturer's instructions (GE Healthcare, Piscataway, NJ). The intensity of protein bands was quantified relative to the signals obtained for actin protein using Java-based image-processing software, ImageJ (W. Rasband (2005) National Institutes of Health, Bethesda, MD, http://rsb.info.nih.gov/ij/).

2.7. Microsomal Incubation and Determination of Cyp1a1 Enzymatic Activity. Microsomes from Liver $(0.25 \mathrm{mg} / \mathrm{mL})$ or lung $(0.15 \mathrm{mg} / \mathrm{mL})$ were suspended in incubation buffer containing $3 \mathrm{mM}$ magnesium chloride hexahydrate dissolved in $0.5 \mathrm{M}$ potassium phosphate buffer $\mathrm{pH} 7.4$ at $37^{\circ} \mathrm{C}$ in a shaking water bath $(100 \mathrm{rpm})$. 7-Ethoxyresorufin was used as a substrate and its final concentration was $2 \mu \mathrm{M}$. A preequilibration period of $5 \mathrm{~min}$ was performed before initiating the reaction with $1 \mathrm{mM} \mathrm{NADPH}$. After an incubation period of $3 \mathrm{~min}$ for liver microsomes and $30 \mathrm{~min}$ for lung microsomes, the reaction was stopped by adding $1 \mathrm{~mL}$ of ice-cold methanol. The reaction was carried out in duplicate using a reaction mixture without NADPH as a blank for each microsome sample. The amount of resorufin in the supernatant of each reaction mixture was determined using the Baxter 96-well fluorescence plate reader using excitation and emission wavelengths of 545 and $575 \mathrm{~nm}$, respectively. Formation of resorufin was linear with incubation time and protein amount. The amount of resorufin was calculated using a standard curve of known resorufin concentrations, and the final amount was calculated by subtracting the amount of resorufin formed in each blank from its corresponding reaction mixture. The final enzymatic activities were expressed as picomole of resorufin formed per minute and per milligram of microsomal proteins.

2.8. Statistical Analysis. All results are presented as mean \pm S.E.M., and statistical differences between treatment groups were determined using one way ANOVA followed by the Student-Newman-Keuls post hoc test using SigmaStat 3.5 program for Windows, Systat Software Inc. (San Jose, CA).

\section{Results}

3.1. Effect of Harmine and Harmaline on Cyp1a1 mRNA, Protein, and Enzymatic Activity in C57BL/6 Mice Livers. Our results showed that treatment of mice with TCDD significantly increased the level of Cyp1a1 mRNA by approximately $200,000 \%$ compared to the control group. Moreover, treatment with harmine significantly decreased TCDD-mediated induction of Cyp1a1 mRNA expression by 15\% (Figure 2(a)).

To examine whether the effect of harmine on hepatic Cypla1 mRNA is translated to a relevant effect at protein and enzymatic activity levels, microsomal fractions were isolated from livers and the effect of harmine on Cypla protein and Cypla1 enzymatic activity was determined using Western blot analysis and 7ER as a substrate, respectively. Our results showed that TCDD induced Cypla protein by $250 \%$ relative to the control group. On the other hand, treatment of harmine significantly decreased TCDD-mediated induction of Cypla protein by $17 \%$ (Figure 2(b)). Moreover, TCDD induced Cypla1 enzymatic activity by $2000 \%$ relative to the control group, whereas harmine treatment significantly decreased TCDD-mediated Cypla1-dependent enzymatic activity by $60 \%$ (Figure $2(\mathrm{c})$ ). 

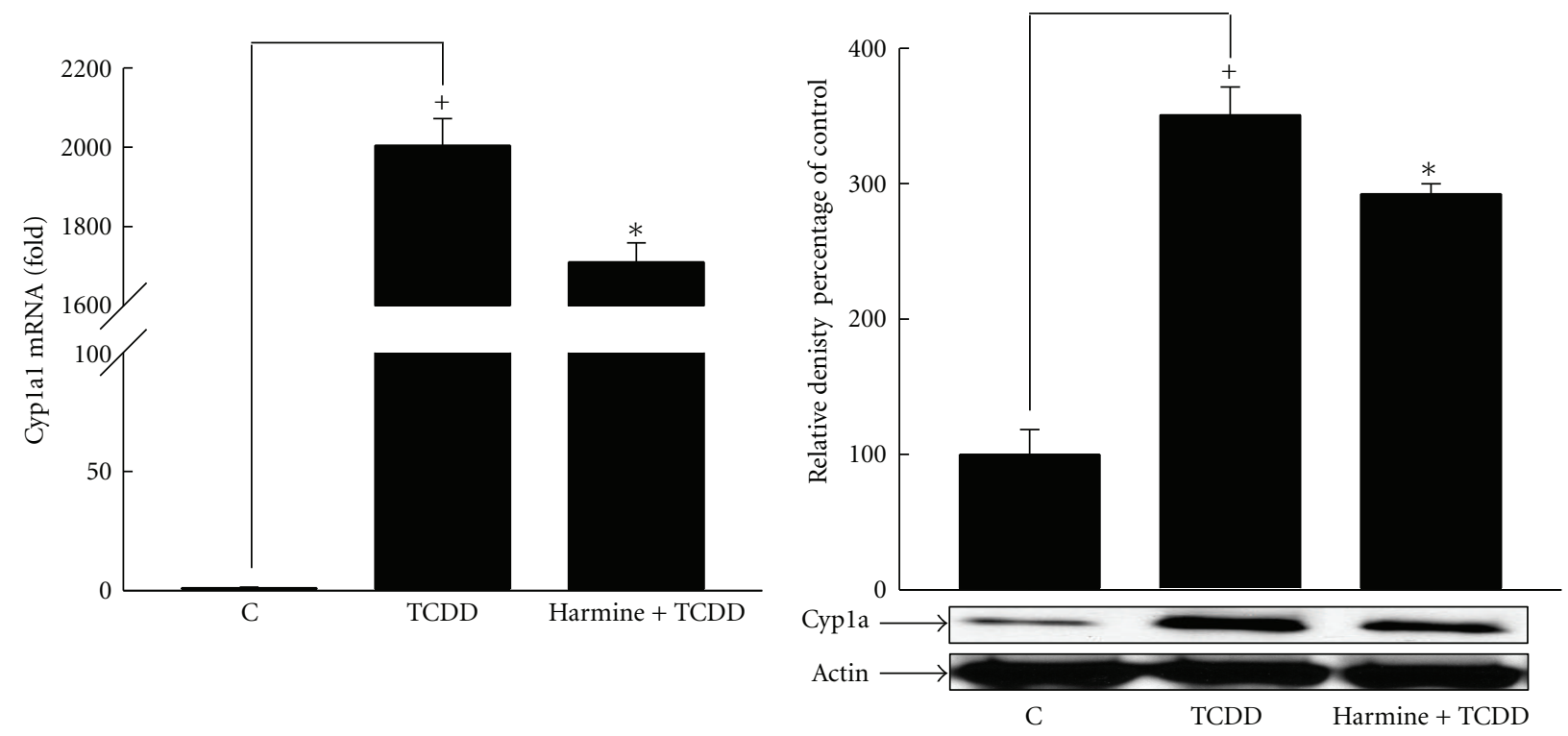

(a)

(b)

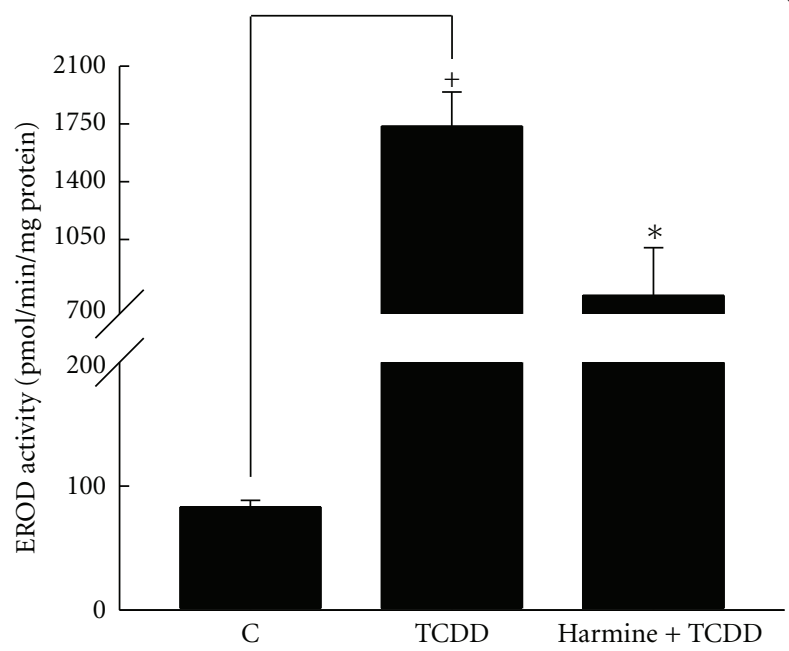

(c)

FIGURE 2: Effect of harmine on TCDD-mediated induction of hepatic Cypla1 at mRNA (a), protein (b), and catalytic activity (c) in C57BL/6 mice. Mice were distributed into several groups, receiving the used vehicle (weight-matched control), TCDD, or TCDD and harmine. After $14 \mathrm{~h}$ from TCDD treatment, mice were sacrificed, and the livers were isolated. Total RNA was isolated using TRIzol reagent, and microsomal fractions were isolated using ultracentrifugation. The level of Cyp1a1 mRNA was determined using real-time PCR (a). Furthermore, Cyp1a protein and Cyplal catalytic activity were determined in microsomal fractions using Western blot analysis (b) and 7ER as a substrate (c), respectively. Values represent the mean \pm S.E.M. $(n=6)$. $(+) P<0.05$ compared to control $(c),(*) P<0.05$ compared to T.

On the other hand, our results showed that harmaline decreased the level of TCDD-mediated induction of Cypla1 mRNA expression by 9\%; however, the effect was not significant (Figure 3(a)). Furthermore, harmaline significantly decreased Cypla protein by $20 \%$ and Cypla1 enzymatic activity by $32 \%$ using Western blotting and 7ER as a substrate, respectively (Figures 3(b) and 3(c)). Collectively, both alkaloids decreased TCDD-mediated induction of Cyp1a1 in liver tissues; however, harmine showed a more pronounced effect especially at Cyp1a1 enzymatic activity level (Table 2).

3.2. Effect of Harmine and Harmaline on Cyp1a1 mRNA, Protein, and Enzymatic Activity Levels in C57BL/6 Mice Lungs. In an effort to examine whether the effect of harmine and harmaline is not specific to liver tissues, lung tissues were isolated, and the effect of both alkaloids on TCDD-mediated induction of Cyplal was determined at mRNA, protein, and enzymatic activity levels. Our results showed that TCDD significantly induced the lung Cypla1 mRNA expression by $43,000 \%$ compared to control group, whereas harmine significantly decreased TCDD-mediated induction of lung Cypla1 mRNA expression by 44\% (Figure 4(a)). Moreover, TCDD caused induction of lung Cypla protein and Cypla1 enzymatic activity by $440 \%$ and $792 \%$, respectively (Figures 4(b) and 4(c)). On the other hand, harmine significantly decreased TCDD-mediated induction of lung Cypla protein and enzymatic activity by $43 \%$ and $60 \%$, respectively (Figures 4(b) and 4(c)). Taken together, these data demonstrate that 


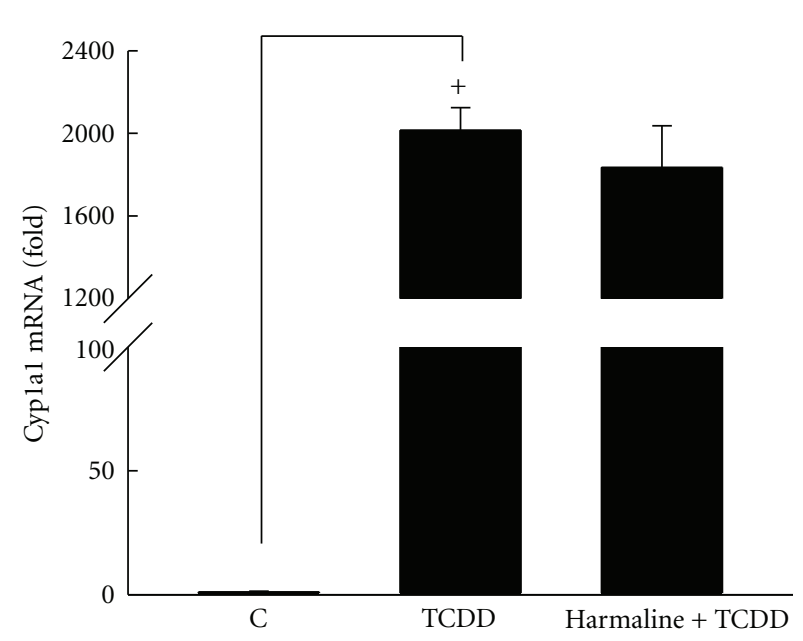

(a)

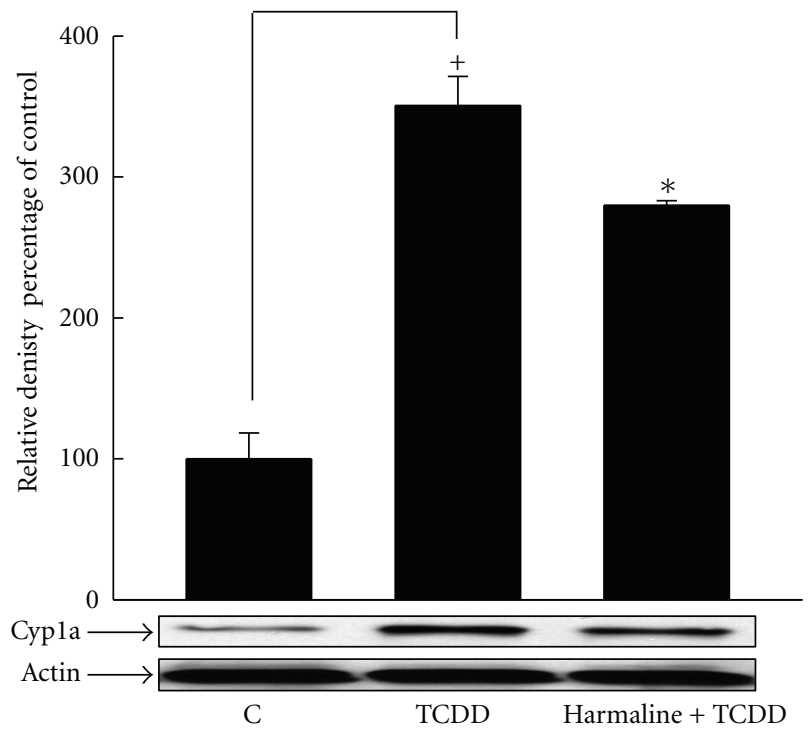

(b)

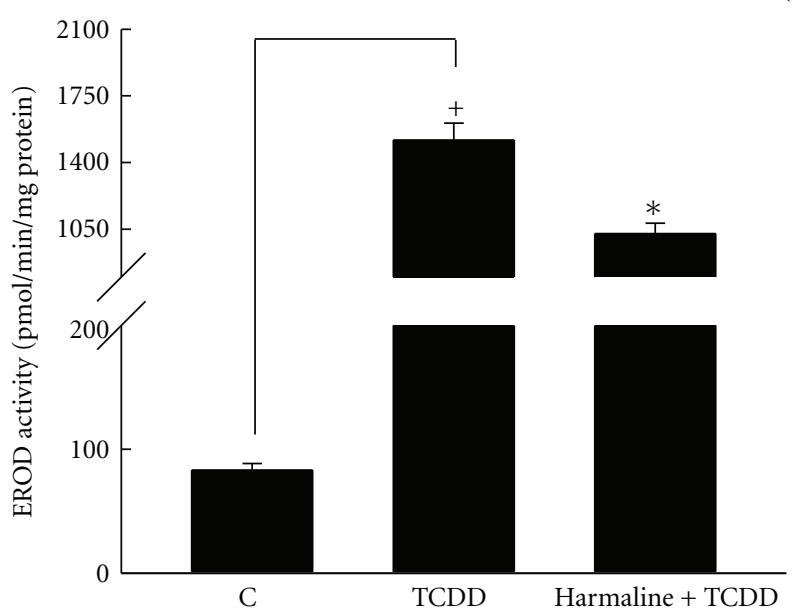

(c)

FIGURE 3: Effect of harmaline on TCDD-mediated induction of hepatic Cypla1 at mRNA (a), protein (b), and catalytic activity (c) in C57BL/6 mice. Mice were distributed into several groups, receiving the used vehicle (weight-matched control), TCDD, or TCDD and harmaline. After $14 \mathrm{~h}$ from TCDD treatment, mice were sacrificed, and the livers were isolated. Total RNA was isolated using TRIzol reagent, and microsomal proteins were isolated using ultracentrifugation. The level of Cyp1a1 mRNA was determined using real-time PCR (a). Furthermore, Cyp1a protein and Cypla1 catalytic activity were determined in microsomal fractions using Western blot analysis (b) and 7ER as a substrate (c), respectively. Values represent the mean \pm S.E.M. $(n=6)$. $(+) P<0.05$ compared to control $(c),(*) P<0.05$ compared to T.

the effect of harmine on TCDD-mediated Cyplal is similar in liver and lung tissues especially at Cyplal enzymatic activity level.

Similar to harmine, we tested the effect of harmaline on TCDD-mediated induction of lung Cyplal at mRNA, protein and enzymatic activity levels. Our results demonstrated that harmaline decreased TCDD-mediated induction of lung Cypla1 mRNA expression by 34\% (Figure 5(a)), whereas, it significantly decreased TCDD-mediated Cyp1a protein and Cypla1 enzymatic activity by $44 \%$ and $40 \%$, respectively (Figures 5(b) and 5(c)). Taken together, these data demonstrate that the effect of harmaline on TCDDmediated Cyplal enzymatic activity is almost the same in lung and liver tissues. Similar to liver tissue, harmine showed a more pronounced effect in decreasing TCDDmediated induction of lung Cypla1 enzymatic activity than that observed with harmaline (Table 2).

\section{Discussion}

The present study demonstrates for the first time that harmine and harmaline significantly decreased the TCDD-mediated induction of the carcinogen-activating enzyme Cyplal in livers and lungs of C57BL/6 mice.

Cancer development is a multistage process that involves several factors. Inherited genetic factors can explain the incidence of $5-15 \%$ of most cancers, but environment and lifestyle are the major factors contributing to cancer 

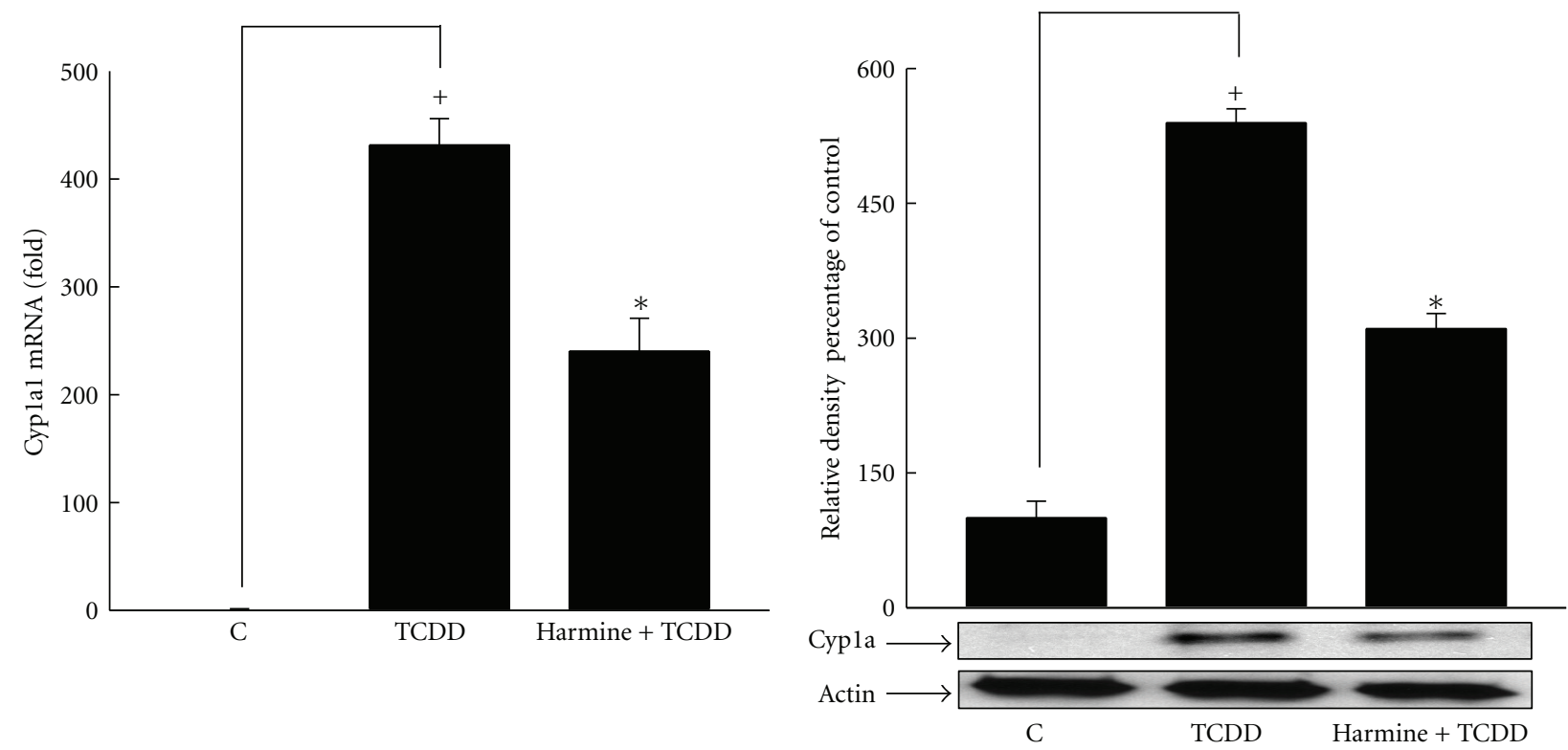

(a)

(b)

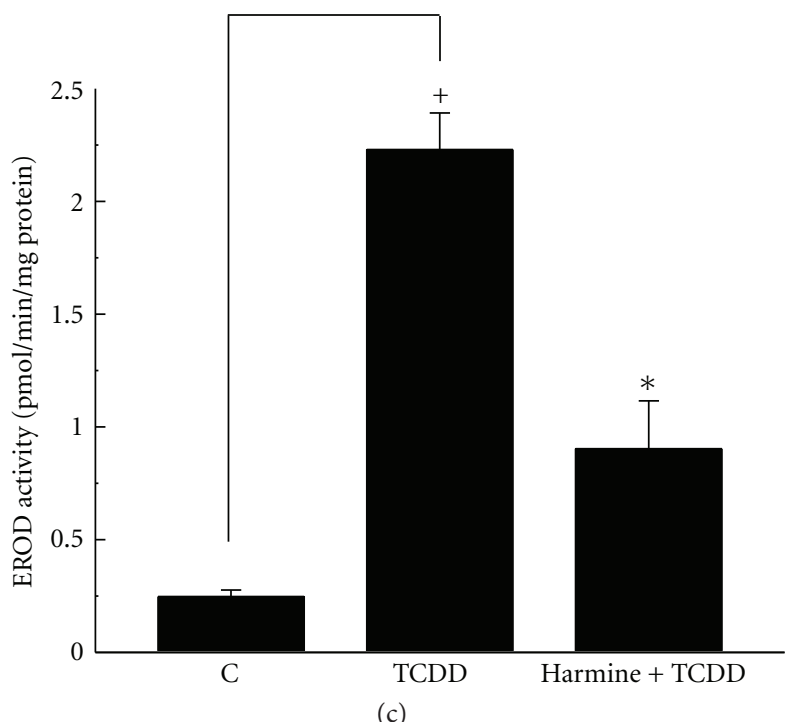

FIGURE 4: Effect of harmine on TCDD-mediated induction of lung Cypla1 at mRNA (a), protein (b), and catalytic activity (c) in C57BL/6 mice. Mice were distributed into several groups, receiving the used vehicle (weight-matched control), TCDD, or TCDD and harmine. After $14 \mathrm{~h}$ from TCDD treatment, mice were sacrificed, and the lungs were isolated. Total RNA was isolated using TRIzol reagent, and microsomal fractions were isolated using ultracentrifugation. The level of Cypla1 mRNA was determined using real-time PCR (a). Furthermore, Cypla protein and Cyplal catalytic activity were determined in microsomal fractions using Western blot analysis (b) and 7ER as a substrate (c), respectively. Values represent the mean \pm S.E.M. $(n=6)$. $(+) P<0.05$ compared to control $(\mathrm{c}),(*) P<0.05$ compared to T.

development [17]. TCDD is a widely distributed environmental pollutant that is usually released in the environment from several sources such as waste incinerators, ferrous and non-ferrous metal production, herbicides manufacturing, and power generation [18]. Several accidents and occupational exposures to TCDD demonstrated the role of TCDD in the increased risk of cancer incidence and mortality [1]. TCDD is a metabolically stable AhR ligand, and several adverse effects of TCDD exposure are related to the persistent activation of the AhR signaling pathway. In agreement with this hypothesis are the results of experiments using transgenic mice in which AhR function has been compromised. It has been demonstrated that the TCDD-mediated adverse effects are attenuated in mice possessing disrupted AhR function $[2,19]$.

Most of the chemical carcinogens in the environment are chemically inert by themselves and require metabolic activation by cytochrome P450 (CYP) enzymes to more reactive metabolites in order to exhibit carcinogenicity in experimental animals and humans [20]. It is well known that AhR 

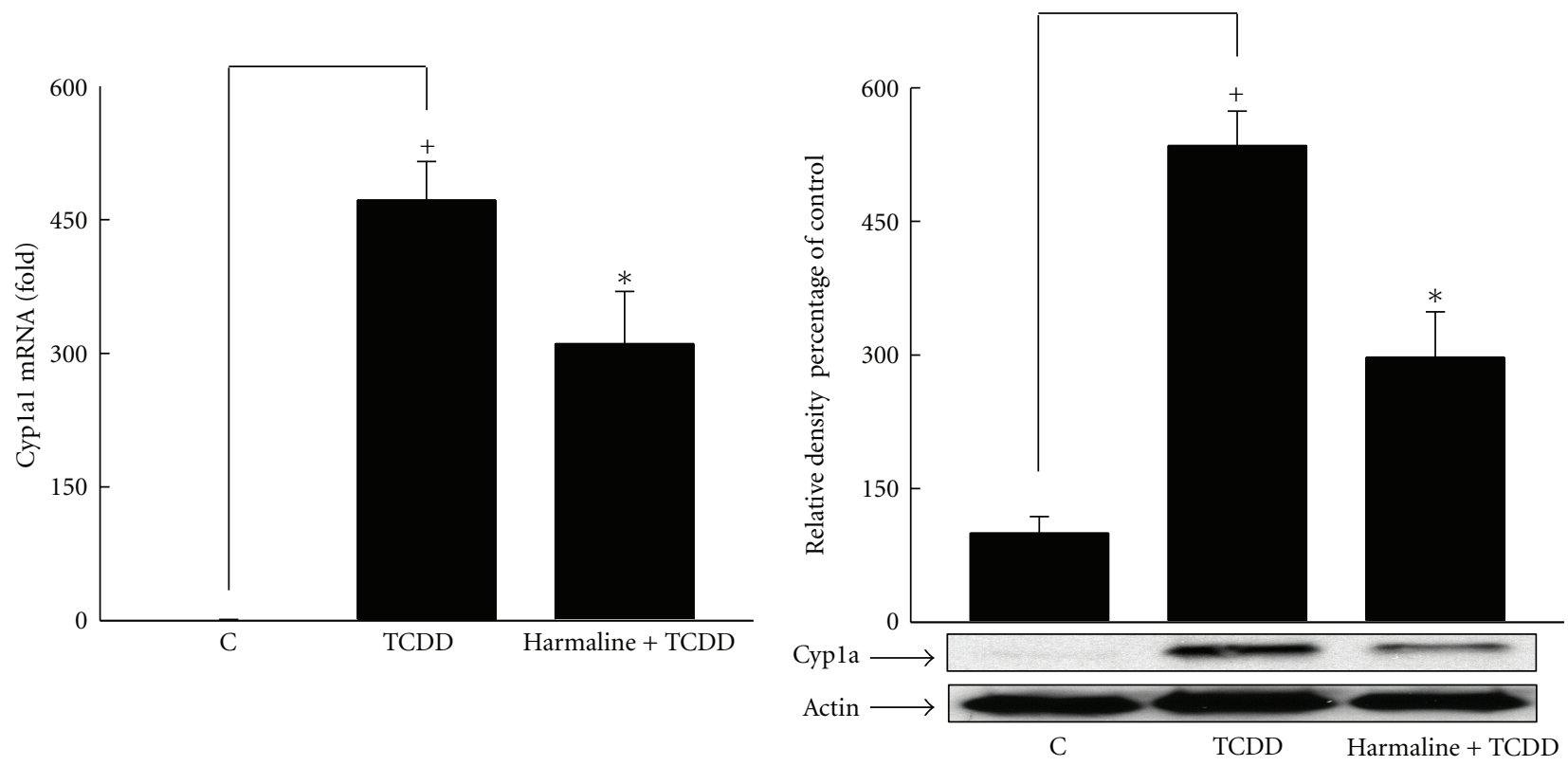

(a)

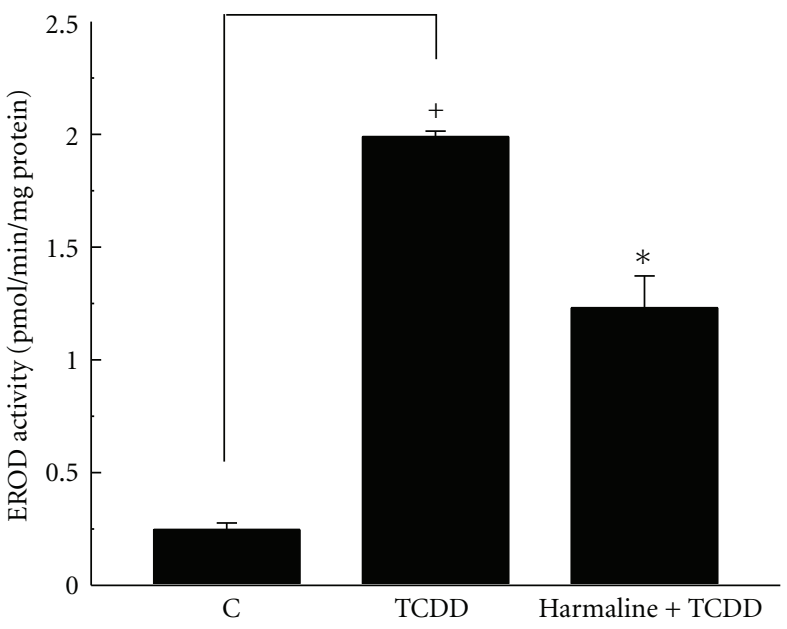

(b)

(c)

FIGURE 5: Effect of harmaline on TCDD-mediated induction of lung Cypla1 at mRNA (a), protein (b), and catalytic activity (c) in C57BL/6 mice. Mice were distributed into several groups, receiving the used vehicle (weight-matched control), TCDD, or TCDD and harmaline. After $14 \mathrm{~h}$ from TCDD treatment, mice were sacrificed, and the lungs were isolated. Total RNA was isolated using TRIzol reagent, and microsomal fractions were isolated using ultracentrifugation. The level of Cypla1 mRNA was determined using real-time PCR (a). Furthermore, Cyp1a protein and Cypla1 catalytic activity were determined in microsomal fractions using Western blot analysis (b) and 7ER as a substrate (c), respectively. Values represent the mean \pm S.E.M. $(n=6)$. $(+) P<0.05$ compared to control $(c),(*) P<0.05$ compared to T.

regulates numerous CYP, such as CYP1A1, that participate in the metabolic activation of several procarcinogens and their conversion to ultimate carcinogenic forms [2]. Consistent with this hypothesis, it has been previously reported that TCDD induces expression of persistent high level of CYP1A1 that leads to increased metabolism of exogenous and endogenous chemicals, generation of reactive oxygen species and induce oxidative stress that results in increased DNA damage $[2,21]$. Moreover, recent reports have highlighted the use of $\mathrm{AhR}$ as a target for new chemopreventative agents. In this context, several AhR antagonists have shown promising results against numerous carcinogenic agents. It has been previously reported that the genotoxicity associated with benzo(a)pyrene in mice was inhibited by AhR antagonists such as $3^{\prime}$-methoxy-4 $4^{\prime}$-nitroflavone and resveratrol $[22,23]$.

Harmine is an aromatic $\beta$-carboline compound that is structurally similar to its dihydro- $\beta$-carboline analogue, harmaline (Figure 1). Both compounds are found naturally in several plants such as Peganum harmala, and they possess several pharmacological effects including antitumor properties. Harmine and harmaline are metabolized in liver and extrahepatic tissues to their main metabolites, harmol, and harmalol, respectively, mainly by CYP2D6 and CYP1A2 (Figure 1) [24]. We have previously demonstrated that both 
TABLE 2: Summary of the effects of harmine and harmaline on TCDD-mediated induction of Cypla1 in livers and lungs of C57BL/6 mice.

\begin{tabular}{lccc}
\hline & & Harmine & Harmaline \\
\hline \multirow{4}{*}{ Liver } & TCDD-induced & & \\
& (i) mRNA Cyp1a1 & $\downarrow 15 \%$ & $\downarrow 9 \%$ \\
& (ii) Protein Cyp1a & $\downarrow 17 \%$ & $\downarrow 20 \%$ \\
& (iii) Activity Cyp1a1 & $\downarrow 60 \%$ & $\downarrow 32 \%$ \\
\hline \multirow{4}{*}{ Lung } & TCDD-induced & & \\
& (i) mRNA Cyp1a1 & $\downarrow 44 \%$ & $\downarrow 34 \%$ \\
& (ii) Protein Cyp1a & $\downarrow 43 \%$ & $\downarrow 44 \%$ \\
& (iii) Activity Cypla1 & $\downarrow 60 \%$ & $\downarrow 40 \%$ \\
\hline
\end{tabular}

harmine and harmaline are capable of inhibiting TCDDmediated induction of Cyplal in murine hepatoma Hepa $1 \mathrm{c} 1 \mathrm{c} 7$ cells [8]. Moreover, we demonstrated that both compounds act as AhR antagonists. Finally, we confirmed that harmine and harmaline possess posttranslational modification by which they reduce the CYP1A1 protein stability in human hepatoma HepG2 cells $[9,10]$. Therefore, we hypothesized that the effect of harmine and harmaline can be translated in vivo using a responsive C57BL/6 mouse strain. Moreover, we tested whether or not the effect of harmine and harmaline can be demonstrated in other extrahepatic tissues, using lung as a representative tissue.

In the current study, we have chosen the C57BL/6 mouse strain as it contains a responsive $\mathrm{AhR}$ allele $\left(\mathrm{AhR}^{b}\right)$ [2]. Regarding the selection of TCDD dose, it is known that TCDD is a metabolically stable compound, and its half-life has been previously determined in mice to be around 20 days [25]. Several concentrations of TCDD have been examined previously for Cyplal induction and AhR activation in the same mouse strain, and it was demonstrated that $15 \mu \mathrm{g} / \mathrm{kg}$ (i.p.) provides a submaximal saturation/activation of the AhR [26]. Additionally, harmine and harmaline doses have been selected according to their half-lives. It has been demonstrated previously that harmine possesses a short half-life in rodents estimated to be around $20 \mathrm{~min}$, whereas harmaline possesses a relatively longer half-life, around $60 \mathrm{~min}$ [27]. Therefore, we thought that multiple doses of both alkaloids would be advantageous. Most importantly, $10 \mathrm{mg} / \mathrm{kg}$ body weight for three doses has been selected based on preliminary experiments, in which we could not detect any effect with lower doses. On the other hand, it is well established that the major drawbacks of using these $\beta$-carboline alkaloids are their tremorgenic side effects [7]. In our study, slight to moderate tremors have been detected for harmine and harmaline in the first dose with higher effect with harmaline. However, these tremors decreased dramatically in the subsequent doses.

There are several reasons behind the choice of liver tissue in our study. First, we have previously studied the effect of harmine and harmaline using different human and murine hepatoma cells. Second, it is well established that TCDD is concentrated in the body mainly in adipose tissue and liver [28]. TCDD is sequestered in the liver by liver-specific microsomal binding proteins [29]. Third, active AhR is an important factor for developing TCDD-mediated hepatocellular toxicity [30]. Finally, the liver is the place of maximum metabolism and highest amounts of CYP enzymes, with a maximum level of CYP1A1 induction. On the other hand, lung has been selected in our study because it is one of the highly exposed organs to environmental pollutants through smoking and air pollutants. Furthermore, several studies have correlated the induction of CYP1A1 enzymatic activity with the development of lung cancer [4].

In the current study, harmine and harmaline significantly decreased TCDD-mediated Cypla1 induction in mice livers and lungs. Harmine showed a greater effect than harmaline in both liver and lung tissues. The differences between the effect of harmine and harmaline can be attributed to two main reasons. First, there is a structural difference between both alkaloids. Harmine has an aromatic planar structure that can enhance its binding ability to AhR, whereas harmaline possesses a coplanar structure. In this context, we have previously demonstrated that harmine efficiently displaced radiolabeled-TCDD in a ligand competition binding assay, whereas harmaline showed a modest effect $[9,10]$. Second, harmine and harmaline possess different pharmacokinetic parameters. It was estimated that the ability of harmine to concentrate in lung is more than that observed for harmaline in rodents [27].

\section{Conclusion}

Harmine and harmaline decrease the TCDD-mediated induction of the carcinogen-activating enzyme Cyplal in C57BL/6 mice livers and lungs. These data provide the first evidence that harmine and harmaline can prevent the adverse effect of dioxins and other AhR ligands in vivo.

\section{Abbreviations \\ AhR: Aryl hydrocarbon receptor \\ CYP1A1: Cytochrome P450 1A1 \\ 7ER: 7-Ethoxyresorufin \\ TCDD: $\quad 2,3,7,8$-Tetrachlorodibenzo-p-dioxin.}

\section{Conflict of Interests}

The authors have declared no conflict of interests.

\section{Acknowledgments}

This work was supported by the Natural Sciences and Engineering Research Council of Canada (NSERC) Grant RGPIN 250139 to A. O. S. El-Kadi. M. A. M. El Gendy is the recipient of the Egyptian government scholarship and the Dissertation Fellowship, University of Alberta.

\section{References}

[1] M. Warner, P. Mocarelli, S. Samuels, L. Needham, P. Brambilla, and B. Eskenazi, "Dioxin exposure and cancer risk in the Seveso Women's Health Study," Environmental Health Perspectives, vol. 119, no. 12, pp. 1700-1705, 2011. 
[2] M. S. Denison, A. A. Soshilov, G. He, D. E. DeGroot, and B. Zhao, "Exactly the same but different: promiscuity and diversity in the molecular mechanisms of action of the aryl hydrocarbon (dioxin) receptor," Toxicological Sciences, vol. 124, no. 1, pp. $1-22,2011$.

[3] T. Shimada, A. Sugie, T. Yamada et al., "Dose-response studies on the induction of liver cytochromes P4501A1 and $1 \mathrm{~B} 1$ by polycyclic aromatic hydrocarbons in arylhydrocarbonresponsive C57BL/6J mice," Xenobiotica, vol. 33, no. 9, pp. 957-971, 2003.

[4] T. Oyama, K. Sugio, H. Uramoto et al., "Cytochrome P450 expression (CYP) in non-small cell lung cancer," Frontiers in Bioscience, vol. 12, no. 6, pp. 2299-2308, 2007.

[5] M. L. Slattery, W. Samowtiz, K. Ma et al., "CYP1A1, cigarette smoking, and colon and rectal cancer," American Journal of Epidemiology, vol. 160, no. 9, pp. 842-852, 2004.

[6] D. Puppala, H. Lee, B. K. Kyung, and H. I. Swanson, "Development of an aryl hydrocarbon receptor antagonist using the proteolysis-targeting chimeric molecules approach: a potential tool for chemoprevention," Molecular Pharmacology, vol. 73, no. 4, pp. 1064-1071, 2008.

[7] R. Cao, W. Peng, Z. Wang, and A. Xu, " $\beta$-carboline alkaloids: biochemical and pharmacological functions," Current Medicinal Chemistry, vol. 14, no. 4, pp. 479-500, 2007.

[8] M. A. M. El Gendy, V. Somayaji, and A. O. S. El-Kadi, "Peganum harmala $\mathrm{L}$. is a candidate herbal plant for preventing dioxin mediated effects," Planta Medica, vol. 76, no. 7, pp. 671-677, 2010.

[9] M. A. M. El Gendy, A. A. Soshilov, M. S. Denison, and A. O. El-Kadi, "Harmaline and harmalol inhibit the carcinogenactivating enzyme CYP1A1 via transcriptional and posttranslational mechanisms," Food and Chemical Toxicology, vol. 50, no. 2, pp. 353-362, 2012.

[10] M. A. M. El Gendy, A. A. Soshilov, M. S. Denison, and A. O. El-Kadi, "Transcriptional and posttranslational inhibition of dioxin-mediated induction of CYP1A1 by harmine and harmol," Toxicology Letters, vol. 208, no. 1, pp. 51-61, 2012.

[11] B. N. M. Zordoky, M. E. Aboutabl, and A. O. S. El-Kadi, "Modulation of cytochrome P450 gene expression and arachidonic acid metabolism during isoproterenol-induced cardiac hypertrophy in rats," Drug Metabolism and Disposition, vol. 36, no. 11, pp. 2277-2286, 2008.

[12] M. A. M. El Gendy and A. O. S. El-Kadi, "Peganum harmala L. differentially modulates cytochrome P450 gene expression in human hepatoma HepG2 cells," Drug Metabolism Letters, vol. 3, no. 4, pp. 212-216, 2009.

[13] T. D. Schmittgen and B. A. Zakrajsek, "Effect of experimental treatment on housekeeping gene expression: validation by real-time, quantitative RT-PCR," Journal of Biochemical and Biophysical Methods, vol. 46, no. 1-2, pp. 69-81, 2000.

[14] K. J. Livak and T. D. Schmittgen, "Analysis of relative gene expression data using real-time quantitative PCR and the 2$\Delta \triangle \mathrm{CT}$ method," Methods, vol. 25, no. 4, pp. 402-408, 2001.

[15] M. M. Barakat, A. O. S. El-Kadi, and P. du Souich, "L-NAME prevents in vivo the inactivation but not the down-regulation of hepatic cytochrome $\mathrm{P} 450$ caused by an acute inflammatory reaction," Life Sciences, vol. 69, no. 13, pp. 1559-1571, 2001.

[16] O. H. Lowry, N. J. Rosebrough, A. L. Farr, and R. J. Randall, "Protein measurement with the Folin phenol reagent," Journal of Biological Chemistry, vol. 193, no. 1, pp. 265-275, 1951.

[17] S. Safe, S. Papineni, and S. Chintharlapalli, "Cancer chemotherapy with indole-3-carbinol, bis $\left(3^{\prime}\right.$-indolyl)methane and synthetic analogs," Cancer Letters, vol. 269, no. 2, pp. 326-338, 2008.

[18] T. V. Beischlag, J. L. Morales, B. D. Hollingshead, and G. H. Perdew, "The aryl hydrocarbon receptor complex and the control of gene expression," Critical Reviews in Eukaryotic Gene Expression, vol. 18, no. 3, pp. 207-250, 2008.

[19] F. J. Gonzalez and P. Fernandez-Salguero, "The aryl hydrocarbon receptor. Studies using the AHR-null mice," Drug Metabolism and Disposition, vol. 26, no. 12, pp. 1194-1198, 1998.

[20] T. Shimada and Y. Fujii-Kuriyama, "Metabolic activation of polycyclic aromatic hydrocarbons to carcinogens by cytochromes P450 1A1 and 1B1," Cancer Science, vol. 95, no. 1, pp. $1-6,2004$.

[21] J. Y. K. Park, M. K. Shigenaga, and B. N. Ames, "Induction of cytochrome P4501A1 by 2,3,7,8-tetrachlorodibenzo-p-dioxin or indolo(3,2-b)carbazole is associated with oxidative DNA damage," Proceedings of the National Academy of Sciences of the United States of America, vol. 93, no. 6, pp. 2322-2327, 1996.

[22] S. D. Dertinger, D. A. Nazarenko, A. E. Silverstone, and T. A. Gasiewicz, "Aryl hydrocarbon receptor signaling plays a significant role in mediating benzo[a]pyrene- and cigarette smoke condensate-induced cytogenetic damage in vivo," Carcinogenesis, vol. 22, no. 1, pp. 171-177, 2001.

[23] A. Revel, H. Raanani, E. Younglai et al., "Resveratrol, a natural aryl hydrocarbon receptor antagonist, protects lung from DNA damage and apoptosis caused by benzo[a]pyrene," Journal of Applied Toxicology, vol. 23, no. 4, pp. 255-261, 2003.

[24] A. M. Yu, J. R. Idle, K. W. Krausz, A. Küpfer, and F. J. Gonzalez, "Contribution of individual cytochrome P450 isozymes to the O-demethylation of the psychotropic $\beta$-carboline alkaloids harmaline and harmine," Journal of Pharmacology and Experimental Therapeutics, vol. 305, no. 1, pp. 315-322, 2003.

[25] R. P. Koshakji, R. D. Harbison, and M. T. Bush, "Studies on the metabolic fate of [14C]2,3,7,8-tetrachlorodibenzo-p-dioxin (TCDD) in the mouse," Toxicology and Applied Pharmacology, vol. 73, no. 1, pp. 69-77, 1984.

[26] D. A. Nazarenko, S. D. Dertinger, and T. A. Gasiewicz, "In vivo antagonism of AhR-mediated gene induction by $3^{\prime}$-methoxy$4^{\prime}$-nitroflavone in TCDD-responsive lacZ mice," Toxicological Sciences, vol. 61, no. 2, pp. 256-264, 2001.

[27] G. Zetler, G. Back, and H. Iven, "Pharmacokinetics in the rat of the hallucinogenic alkaloids harmine and harmaline," NaunynSchmiedeberg's Archives of Pharmacology, vol. 285, no. 3, pp. 273-292, 1974.

[28] K. Hu and N. J. Bunce, "Metabolism of polychlorinated dibenzo-p-dioxins and related dioxin-like compounds," Journal of Toxicology and Environmental Health B, vol. 2, no. 2, pp. 183-210, 1999.

[29] J. J. Diliberto, D. Burgin, and L. S. Birnbaum, "Role of CYP1A2 in hepatic sequestration of dioxin: studies using CYP1A2 knock-out mice," Biochemical and Biophysical Research Communications, vol. 236, no. 2, pp. 431-433, 1997.

[30] M. Nukaya, J. A. Walisser, S. M. Moran, G. D. Kennedy, and C. A. Bradfield, "Aryl hydrocarbon receptor nuclear translocator in hepatocytes is required for aryl hydrocarbon receptor-mediated adaptive and toxic responses in liver," Toxicological Sciences, vol. 118, no. 2, pp. 554-563, 2010. 

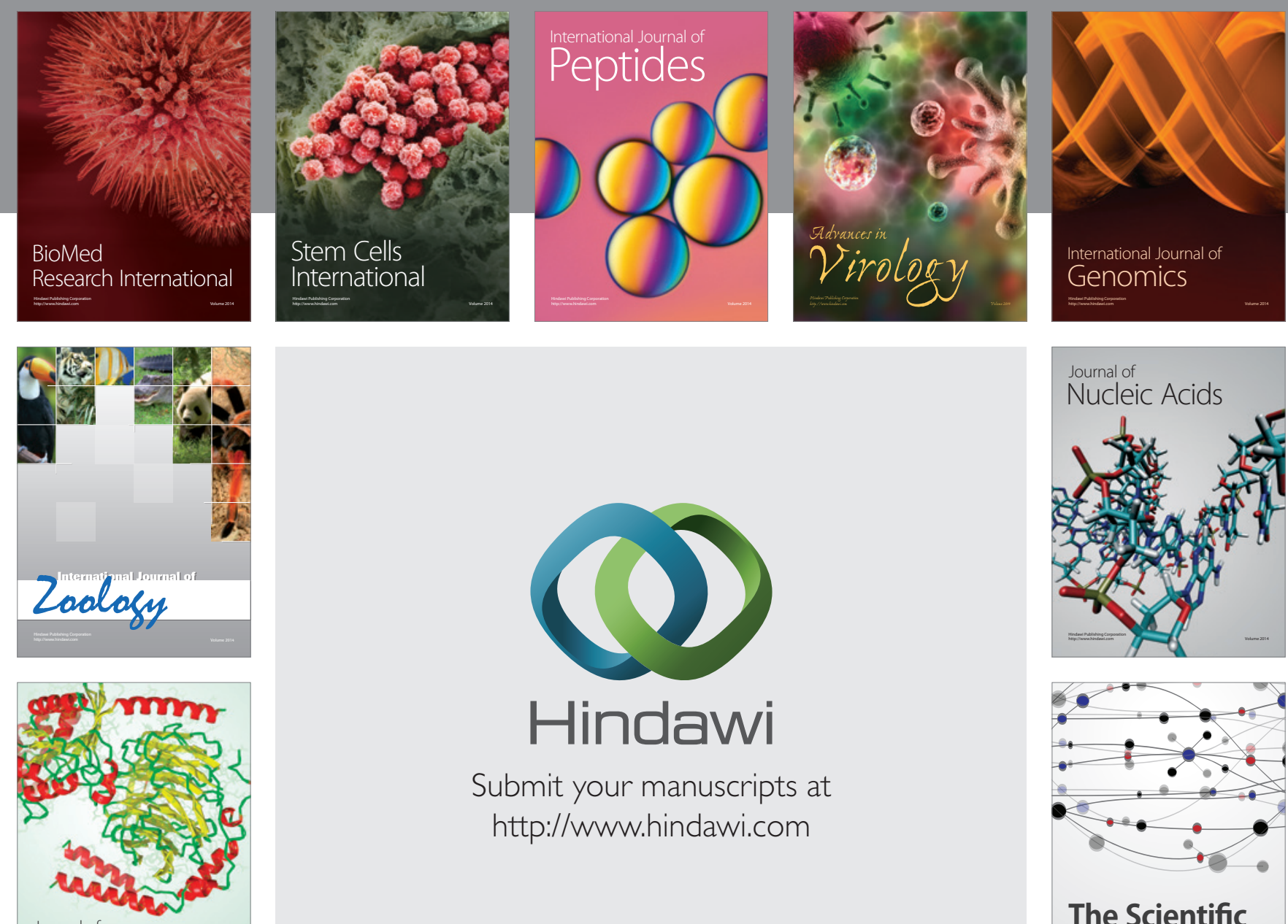

Submit your manuscripts at

http://www.hindawi.com

Journal of
Signal Transduction
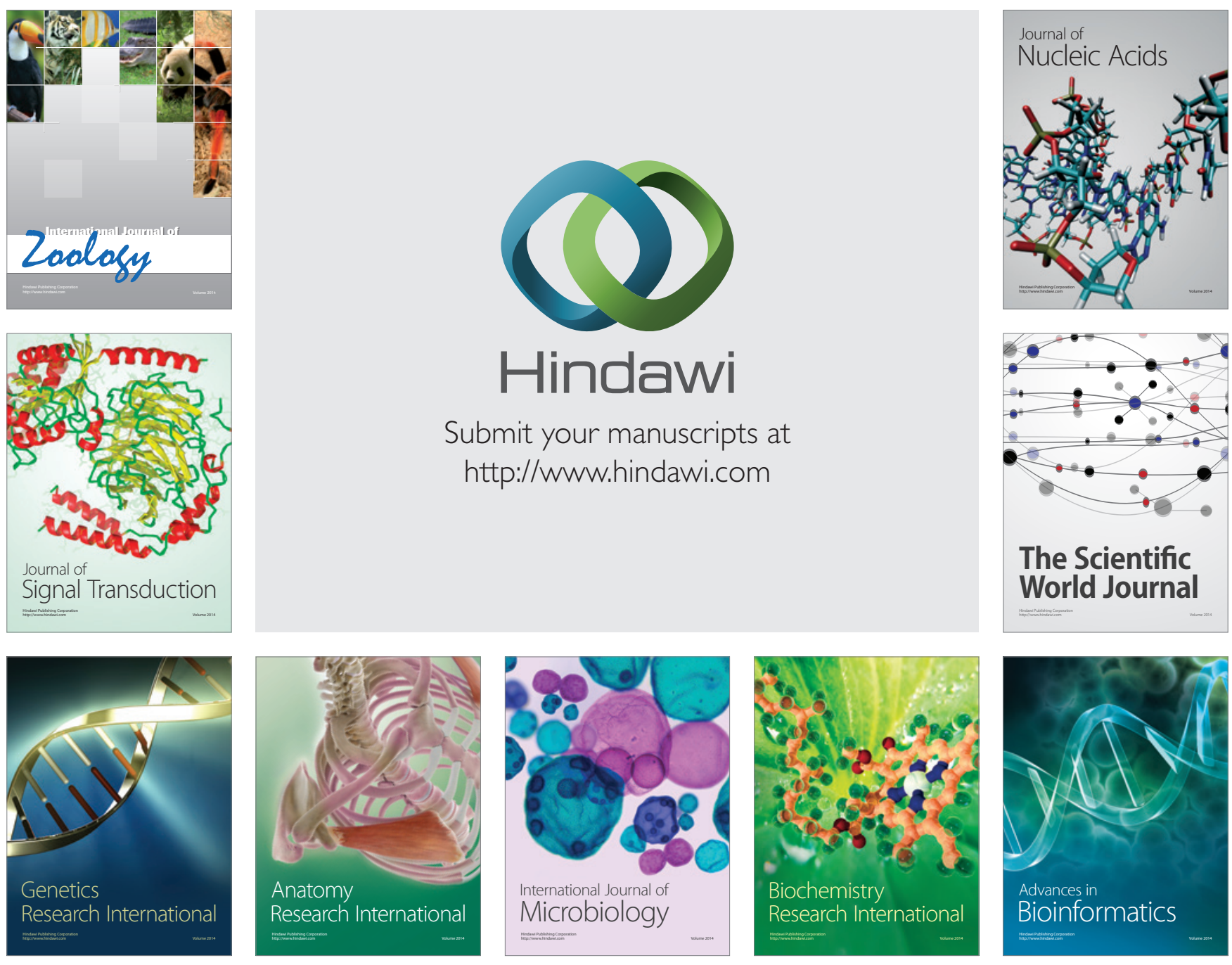

The Scientific World Journal
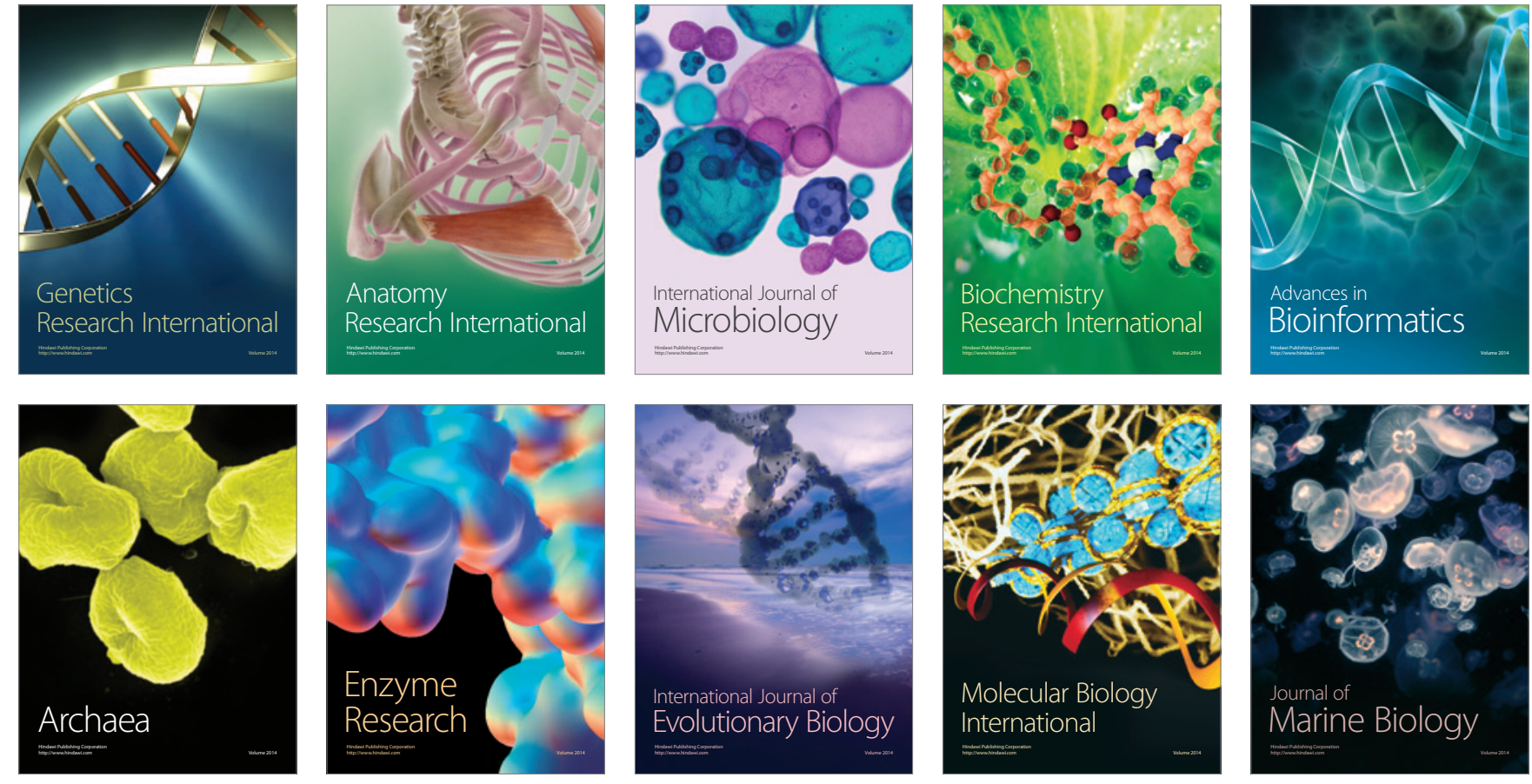